\title{
INTERVENÇÕES NA EMERGÊNCIA: A ESCUTA PSICANALÍTICA PÓS-DESASTRE NA BOATE KISS
}

\author{
Interventions in the Emergency: The Post-disaster Psychoanalytic Listening of the Boate \\ Kiss
}

\author{
Intervenciones en la Emergencia:La Escucha Psico-analítica Post-desastre de la Boate Kiss \\ Interventions en cas D'urgence: L'écoute Psychanalytique après la Catastrophe chez la \\ Boate Kiss
}

\begin{abstract}
Alice Moreira da Costa
Especialista em Saúde da Família e Comunidade pelo Grupo Hospitalar Conceição, mestranda do Programa de Pós-Graduação em Psicologia da Universidade Federal de Santa Maria, bolsista CAPES/DS.
\end{abstract}

Maria Luiza Leal Pacheco

Mestre em Psicologia Clínica, PUCRS e Especialista em Atendimento Clínico ênfase em Psicanálise, UFRGS, Psicóloga do Acolhe Saúde, Secretaria Municipal de Saúde, Prefeitura Municipal de Santa Maria.

Cláudia Maria Perrone Doutora em Psicologia pela PUCRS, Professora Associada I do Departamento de Psicologia da Universidade Federal de Santa Maria.

Recebido em: 06/08/2015 / Revisado em: 14/01/2016 / Aceito em: 01/03/2016

\section{Resumo}

As situações de desastre agrupam um conjunto de fenômenos psíquicos que se formam em consequência da intrusão de um evento limite, na maior parte das vezes imprevisível, que causa um impacto intenso no psiquismo. Tal acontecimento pode ser da ordem do inominável e provocará uma desorganização psíquica com fator traumático. Na cidade de Santa Maria, Rio Grande do Sul, ocorreu um incêndio, no dia 27 de janeiro de 2013, que ocasionou 242 mortes e teve um impacto potencialmente traumático. O trauma não é o fato em si, mas a forma como um evento disruptivo incide sobre o aparelho psíquico dos sujeitos e como é articulado na vivência singular. Diante disso, é fundamental a atenção aos possíveis efeitos do traumático sobre o psiquismo com o objetivo de criar intervenções terapêuticas eficazes, que facilitem o processo de simbolização do excesso de estímulo, possibilitando a narrativa da vivência. Será apresentado um relato de experiência profissional que articula a teoria psicanalítica com a escuta clínica realizada por psicólogos de orientação psicanalítica diante de uma emergência.

Palavras-chave: trauma; psicanálise; emergência; narrativa; desastre.

\section{Abstract}

Disaster situations group together a set of psychic phenomena that are formed as a consequence of the intrusion of a limiting event, most of the time unpredictable that causes an intense impact on the psyche. Such an event may be of unnamable order and will provoke a psychic disorganization with a traumatic factor. In the city of Santa Maria, Rio Grande do Sul, a fire on January 27, 2013, caused 242 deaths and had a potentially traumatic impact. The trauma is not the fact itself, but the way a disruptive event affects the psychic apparatus of the subjects and how it is articulated in the singular experience. In view of this, it is essential to be aware of the possible effects of the traumatic on the psyche with the objective of creating effective therapeutic interventions that facilitate the process of symbolizing the excess of stimulus, allowing the experience narrative. It will be presented an report of professional experience that articulates the 
psychoanalytic theory with the clinical listening performed by psychoanalytically oriented psychologists in the face of an emergency.

Keywords: trauma; psychoanalysis; emergency; narrative; disaster.

\section{Resumen}

Las situaciones de desastre reúnen un conjunto de fenómenos psíquicos que son formados en consecuencia de la intrusión de un evento límite, en la mayoría de los casos imprevisible, que causa un intenso impacto psíquico. El ocurrido puede ser del orden innominable y provocará un desorden psíquico con factor traumático. En la ciudad de Santa Maria, Rio Grande do Sul, ocurrió un incendio, en el día 27 de enero de 2013, que causo 242 muertes y tuvo un impacto potencialmente traumático. El trauma no es el hecho en sí, pero la forma como el evento disruptivo ocurre sobre el aparato psíquico de los sujetos y como es articulado en la vivencia singular. Ante esto, es fundamental estar atento a los posibles efectos del traumático sobre el psiquismo con el objetivo de crear intervenciones terapéuticas eficientes que faciliten el proceso de simbolización del exceso de estímulos, posibilitando la narrativa de la vivencia. Será presentado un informe de experiencia profesional que articula la teoría psico-analítica con la escucha clínica realizada por psicólogos de orientación psico-analítica ante una emergencia.

Palabras clave: trauma; psico- análisis; emergencia; narrativa; desastre.

\section{Résumé}

Les catastrophes assemblent des phénomènes psychologiques qui se sont formés à cause de l'intrusion d'un événement, généralement imprévisible, ce qui provoque un lourd impact sur le psychisme. Un tel événement peut être de l'ordre de l'innommable et ira provoquer une désorganisation psychique avec facteur traumatique. Dans la ville de Santa Maria, Rio Grande do Sul, un incendie a éclaté le 27 Janvier 2013, qui a causé 242 décès et a eu un impact potentiellement traumatique. Le traumatisme n'est pas le fait lui-même, mais la façon comment un événement perturbateur se concentre sur l'appareil psychique des sujets et comment l'événement est énoncé dans l'expérience singulière. Par conséquent, il est essentiel d'être conscient des effets possibles d'un traumatisme sur la psyché, afin de créer des interventions thérapeutiques efficaces qui facilitent le processus de symbolisation de stimulation excessive, ce qui permet le récit d'expérience. Il va être présenté un rapport d'expérience professionnelle qui articule la théorie psychanalytique et l'écoute clinique menée par des psychologues psychanalytiques en cas d'urgence.

Mots-clés: traumatisme; urgence; psychanalyse; récit; catastrophe.

Os traumas históricos afetam invariavelmente a autoconservação e a autopreservação de uma comunidade. Sendo assim, eventos potencialmente traumáticos, como desastres, violências, guerras, dentre outras situações que produzem grave ameaça à vida, podem influenciar substancialmente no funcionamento do psiquismo dos sujeitos, causando consequências inomináveis, difíceis de serem simbolizadas (Fuks, 2010).

O trauma não é o fato em si, mas a forma como um evento disruptivo incide sobre o aparelho psíquico dos sujeitos e como é articulado na vivência singular. As experiências da ordem do traumático podem romper de forma radical a organização psíquica, provocando um desarranjo em seu funcionamento habitual, precipitando em uma série de sintomas psicopatológicos (Rudge, 2009). Diante disso, é fundamental a atenção aos possíveis efeitos do traumático sobre o psiquismo com o objetivo de criar intervenções terapêuticas eficazes, que facilitem o processo de reorganização psíquica e simbolização da experiência, possibilitando a narrativa da vivência.

Na cidade de Santa Maria, RS, na madrugada do dia 27 de janeiro de 2013, ocorreu um incêndio que teve um impacto potencialmente traumático. Tal desastre destruiu uma casa noturna denominada Kiss e ocasionou a morte de 242 pessoas, deixando inúmeros feridos (Boletim SMS, 2013). Esse incêndio, que foi amplamente noticiado e gerou grande comoção nacional e internacional. A maioria das vítimas era composta de jovens universitários que frequentavam a boate em função de uma festa promovida por grupos de alunos das universidades da cidade.

Este artigo tem como objetivo apresentar dados parciais de uma pesquisa, realizada no Programa de Pós-Graduação em Psicologia da Universidade Federal de Santa Maria, cujo objetivo foi coletar relatos de experiência profissional de psicólogos de orientação psicanalítica que participaram do atendimento das vítimas do desastre. As intervenções, propostas no atendimento e descritas neste trabalho, envolvem o processo de construção de redes de apoio psicossocial diante de uma emergência e sua articulação com a escuta psicanalítica em situações da ordem do traumático. 
Participaram da pesquisa oito psicólogos da rede de saúde mental de Santa Maria e de outras regiões do país, que se autodeclararam de orientação psicanalítica e trabalharam no atendimento com a população afetada pelo desastre na boate Kiss. A coleta dos dados foi realizada através de entrevistas semiestruturadas. Foram convidados a participar da amostra 13 (treze) psicólogos que atendiam o critério de inclusão de pertencer à orientação psicanalítica. No entanto, cinco profissionais não se sentiram em condições de participar da pesquisa. As entrevistas foram transcritas e foi realizada análise temática de conteúdo.

Entendemos que a atenção aos preceitos éticos de pesquisa com seres humanos impede uma pesquisa, pelo objetivo proposto neste trabalho, com os sobreviventes do desastre, pois existe o risco de retraumatização. A estratégia encontrada foi a realização de entrevistas com os psicólogos envolvidos no cuidado das pessoas afetadas. Ainda que existam limitações nessa estratégia de pesquisa, acreditamos que ela contribui para o conhecimento, desenvolvimento e aperfeiçoamento de tecnologias de cuidado em desastres, especialmente para a população afetada pelo evento. Os profissionais entrevistados trabalharam diretamente no cuidado destinado às pessoas afetadas emocionalmente pelo incêndio da boate Kiss durante o primeiro ano pós-desastre. A aprovação do Comitê de Ética em pesquisa para a realização deste estudo foi obtida em 12 de janeiro de 2015, e está sob o número CAEE 39125614.5.0000.5346.

\section{O Desastre na Casa Noturna e os Primeiros Atendimentos}

Os primeiros atendimentos aos afetados pelo incêndio, segundo dados da Secretaria de Saúde do Estado do Rio Grande do Sul (Boletim SMS, 2013) foram prestados pelo Serviço de Atendimento Móvel de Urgência (SAMU) de seis municípios, e a internação dos sobreviventes contou com vagas em 13 hospitais de cinco cidades (Boletim SMS, 2013). Diante de tal cenário, o foco dos atendimentos pré-hospitalares, de urgência e emergência, foi prestado não apenas pelo SAMU, mas também por táxis e carros particulares de pessoas que se disponibilizaram a auxiliar no transporte dos sobreviventes que precisavam de cuidados médicos.

Os atendimentos de urgência e emergência foram realizados pelos hospitais de Santa Maria e região; os casos mais graves, porém, foram transferidos para a capital do Estado, Porto Alegre. Tal ação contou com o auxílio do SAMU, do Exército e da Força Aérea Brasileira (Boletim SMS, 2013). Uma força-tarefa foi montada com o objetivo de garantir vagas de tratamento intensivo em hospitais especializados na capital do Estado e região metropolitana, bem como organizar o acolhimento aos pacientes graves que foram transferidos.

Em Santa Maria, três hospitais concentraram as internações de feridos. Estabelecimentos de saúde de Caxias do Sul e Ijuí também receberam pacientes, totalizando 13 hospitais envolvidos em todo o estado do Rio Grande do Sul. Durante o tratamento dos pacientes, as equipes das Unidades de Tratamento Intensivo (UTIs) de todos os hospitais participaram de videoconferências para troca de experiências sobre medidas exitosas no acompanhamento de cada caso (Boletim SMS, 2013).

Um acontecimento dessa magnitude deve ser classificado como "desastre" ou "evento crítico". No Brasil, vige atualmente a Instrução Normativa $n^{\circ} 1$, baseada na Lei 12.608/2012, na qual se encontra uma definição corrente desses diferentes termos com base numa análise do tipo de desastre (Nível I ou II), das características, dos danos (humanos, materiais e/ou ambientais) e prejuízos para o território que um determinado evento acarreta.

Conforme o Manual da Defesa Civil (2013), o qual analisa os danos e prejuízos no país resultantes de eventos adversos, naturais ou provocados pelo homem sobre um ecossistema vulnerável, tais situações podem causar danos materiais, humanos e ambientais, e posteriores prejuízos econômicos e sociais. Assim, o desastre se caracteriza conforme a intensidade do impacto ocasionado na população atingida, ou seja, está ligado à magnitude do evento e, em especial, ao grau de vulnerabilidade do sistema afetado, pois não é o evento em si que está em jogo, mas a consequência dele em um ambiente vulnerável.

Conforme a Cartilha para a Intervenção em Catástrofe (2009), os desastres são situações que atingem uma população considerada saudável, em que recai sobre ela uma situação inesperada que desorganiza a vida de forma violenta e, por vezes, traumatizante. Tais situações atingem o potencial de equilíbrio das pessoas envolvidas, desestruturando os sujeitos emocional e psiquicamente, podendo gerar sentimentos de insegurança, descrença e desamparo.

Além disso, o incêndio teve um caráter de extrema imprevisibilidade, e a cidade e as pessoas envolvidas não tinham estrutura para suprir as demandas que foram instauradas de forma intensa. A cidade de Santa Maria precisou de uma forçatarefa, a qual contou com o auxílio de muitos profissionais voluntários assessorados pelo Médicos Sem Fronteiras e por representantes da gestão pública na área de saúde mental, que conduziram a organização dos processos de trabalho em caráter emergencial.

Em função da dimensão do desastre, muitas pessoas foram retiradas sem vida da casa noturna. Cerca de 230 jovens foram conduzidos por caminhões até o Centro Desportivo Municipal (CDM) com o objetivo de sistematizar a identificação 
e liberação dos corpos. Foram utilizados cinco caminhões do Exército para tal finalidade. A escolha do local ocorreu em função do Instituto Médico-Legal (IML) comportar somente 10 mortos. Tal organização foi dada em um tempo estimado de quatro horas no que se refere ao carregamento e à organização das vítimas no CDM (Boletim SMS, 2013).

Após a etapa de transporte dos corpos, foram realizadas ações com o objetivo de dar procedimento à identificação dos mortos pelos familiares. Esse momento foi marcado por intensa angústia e sofrimento. As famílias percorriam a cidade desde as três horas da madrugada na busca por informações. Um setor de urgência e emergência em saúde foi organizado com o objetivo de dar suporte emocional aos familiares. Para coordenar as ações, foram montadas as seguintes equipes: equipe responsável pelas medicações, equipe responsável pelo acolhimento e a equipe responsável pelas doações (água e alimentos). É importante ressaltar que as famílias atingidas pertenciam não somente à região de Santa Maria, mas a várias regiões do estado do Rio Grande do Sul, marcando o caráter estadual do evento.

Outra frente de cuidado humanitário foi o reforço de ambulâncias de plantão na entrada do CDM, com o intuito de prestar atendimento e apoio em situações de emergência. Paralelamente a essa ação, profissionais da Secretaria Municipal de Saúde realizaram o cadastramento dos voluntários por categorias profissionais para estabelecerem a atuação de equipes multidisciplinares para atendimento no local. Profissionais voluntários foram organizados para oferecer suporte ao acompanhamento dos familiares na identificação dos corpos e auxiliar na mediação e na contenção das situações de desespero (Boletim SMS, 2013).

O trabalho de acolhimento após uma situação de desastre é fundamental, porque possibilita que o sujeito possa enfrentar e criar um significado para a vivência traumática. Tal intervenção contribuiu no processo de representação psíquica do ocorrido, estabeleceu uma possibilidade para a representação da vivência que não aprisionasse os sujeitos na angústia de aniquilamento que desampara e desorganiza. Profissionais da saúde, em especial os psicólogos, puderam oferecer uma escuta terapêutica aos que sofreram essa experiência impactante. Por meio dessa aliança de trabalho, os técnicos buscaram formas de acolher os sujeitos, criando um vínculo mínimo que estabilizasse, auxiliasse na identificação de fragilidades e no desenvolvimento de formas de enfrentamento (Cartilha para a intervenção em catástrofe, 2009; Selligman-Silva, 2000; Thomé, 2012).

Uma das situações mais difíceis vividas após o desastre foi o reconhecimento do corpo por um familiar. Nessa vivência, o sujeito sofre o primeiro impacto, o choque, e responde com uma regressão psíquica aguda que pode desencadear até sintomas psicóticos. Foi proposta, como estratégia de cuidado aos familiares, a presença de um psicólogo para o acompanhamento no reconhecimento dos corpos, bem como o suporte paralelo de uma equipe de saúde, caso fosse necessário algum tipo de intervenção clínica devido à intensa mobilização emocional de se deparar com um(uma) filho(a)/familiar morto.

Nesse momento, considerado crítico, foram observados pelos profissionais de saúde casos de hipertensão arterial, situações de descontrole emocional e princípio de infarto, com a necessidade de remoção de familiares para atendimentos especializados fora do CDM. Tal circunstância de intenso sofrimento pode ser remetida à desorganização psíquica frente ao irrepresentável diante do real da morte repentina.

\section{A Vivência Traumática: Frente ao Intraduzível Provocado por um Desastre}

O trauma é considerado um acontecimento intenso que o sujeito vivencia e que o impossibilita de reagir de forma adequada devido aos efeitos patogênicos disruptivos provocados na organização psíquica. Em termos econômicos, o trauma se manifesta por um afluxo de excitação excessiva em relação à tolerância do sujeito e à sua capacidade de dominar e elaborar psiquicamente a quantidade significativa de energia pulsional desligada no aparelho psíquico (Dunker, 2006; Freud, 1920/2010; Fuks, 2010; Laplanche, 2001; Rudge, 2009; Uchitel, 2001). O traumático refere-se ao excesso de excitação pulsional que irrompe no psiquismo e impossibilita a capacidade de simbolização, causando efeitos disruptivos para o sujeito.

O trauma designa uma lacuna na memória pela não inscrição da experiência no psiquismo, pelo bloqueio dos processos de simbolização, pela falta de sentido, o que ocasiona falhas na relação do sujeito com a realidade externa, ou seja, o traumático ocorre quando a realidade externa, de caráter violento, não consegue ser assimilada pelo psiquismo (Fuks, 2010; Rudge, 2009; Selligman-Silva, 2000). O fator traumático está relacionado aos limites do eu no que se refere à sua capacidade de processar a irrupção pulsional, configurando uma situação de violência psíquica.

A vivência poderá ser considerada traumática nos casos em que o sujeito presencia uma situação de intenso sofrimento, como a ocorrida no incêndio da casa noturna, tanto para os sobreviventes como para as pessoas que sofreram seus efeitos. Situações como o reconhecimento do corpo de um ente querido, por exemplo, fogem do plano da significação, pois o acontecimento gera excesso de angústia que o sujeito não consegue simbolizar nem representar por meio da palavra. O afluxo de excitações da ordem do traumático impossibilita o aparelho psíquico de traduzir, dominar e elaborar uma situação 
abrupta como a testemunhada (Fuks, 2010; Rudge, 2009).

À medida que os corpos foram reconhecidos, ficou clara a necessidade de organizar um velório coletivo no CDM, pois não havia infraestrutura na cidade para acolher o número significativo de óbitos. Esse foi o modo de garantir os ritos de despedida, indispensáveis para exprimir e solidificar vínculos, suscitando uma partilha de emoções que assegurasse um mínimo de elaboração coletiva do luto e de coesão social.

\section{Apoio Psicossocial: Uma Rede para o Enfrentamento do Traumático}

Uma situação como a ocorrida na boate Kiss pode configurar uma vivência potencialmente traumática. Oliveira e Dassoler (2014) destacam que, segundo os Médicos Sem Fronteiras, esse incêndio agrupou três situações com uma significativa potencialidade traumática em um único evento: ocorreu com um público jovem, com um número expressivo de vítimas (242 mortes) e irrompeu de forma abrupta e violenta em um local inesperado (local festivo). Os autores (2014, p. 31) afirmam ainda que tal fato assume uma coloração traumática por promover uma ruptura radical, inesperada e intensa na rotina construída, na qual passado, presente e futuro se ligam e elaboram um tipo particular de ficção, que é designada como a história de cada um.

Em um evento como esse, de proporções estaduais, pudemos entender a importância de construir uma rede de apoio psicossocial para atender as pessoas envolvidas, direta e indiretamente, no desastre, já que se estimava que um número significativo de pessoas atingidas poderiam apresentar sintomas da ordem do traumático. Diante de um desastre dessa magnitude, psicólogos trabalharam em conjunto com outros profissionais de diferentes áreas no processo de construção e planejamento de um trabalho de escuta.

Um serviço de apoio psicossocial foi organizado, possibilitando aos envolvidos a criação de sentido para a vivência do traumático. Como a psicanálise poderia intervir na urgência e emergência de um desastre com esse potencial traumático? Qual escuta seria possível? Quais demandas iriam aparecer? Será que, enquanto psicanalistas, estavam preparados para oferecer esse tipo de escuta? Eram muitas perguntas sem resposta. Porém, diante de uma demanda constituída, havia a necessidade de montar um serviço que pudesse receber esses sujeitos.

Além disso, era claro que a rede de atenção psicossocial da cidade não teria como suprir a demanda em tal proporção de sujeitos afetados, pois deveriam participar desse cálculo as pessoas impactadas indiretamente (pessoas que não estavam na boate, mas que perderam amigos, conhecidos ou que apresentaram desorganizações psíquicas decorrentes do desastre, necessitando também de acompanhamento especializado). É importante ressaltar a necessidade de cuidado psicossocial destinado também aos profissionais da saúde e de segurança pública que ajudaram no resgate das vítimas e sobreviventes, como técnicos da área da saúde, soldados, bombeiros, motoristas de táxi e até civis que auxiliaram no transporte dos corpos. Os três entes federativos (município, estado e união) firmaram um pacto que estabeleceu a assistência especializada por cinco anos, renovável por mais cinco, direcionada às pessoas afetadas pelo desastre, de forma direta ou indireta. Foi implementado um serviço atípico com o objetivo de assegurar o atendimento psicossocial longitudinal das pessoas afetadas emocionalmente pelo incêndio. $\mathrm{O}$ atendimento psicossocial ficou sob a responsabilidade do município para organizar e delinear ações efetivas locais no enfrentamento das situações dessa natureza, desencadeadas em virtude do desastre na boate Kiss (Boletim SMS, 2013; Oliveira \& Dassoler, 2014).

$\mathrm{O}$ trabalho de articulação de redes de apoio psicossocial diante do incêndio na boate foi mediado através da criação de um serviço inédito no país, regido pelo Sistema Único de Saúde, para planejamento e execução de ações de saúde que atingissem diferentes esferas da população. Diversos dispositivos, tanto clínicos como institucionais, foram organizados, incluindo: atendimentos especializados; acolhimentos; visitas domiciliares; participação em ações coletivas promovidas pelos pais de vítimas e sobreviventes; apoio na gestão dos processos institucionais; bem como a realização do trabalho matricial pelas equipes de atenção básica. O serviço, nomeado Acolhe Saúde, atualmente é referência na cidade de Santa Maria em situações de morte, luto, tentativas de suicídio e suicídio, e recebe vários encaminhamentos dessa natureza. O serviço é considerado uma experiência bem-sucedida por diferentes autoridades e instituições, em termos de intervenção em desastre, no que se refere ao atendimento psicossocial (Dassoler, Mafacioli, Pacheco, Bueno, Sanfelice, \& Fighera, 2016). Ao final do primeiro ano após o desastre, o Acolhe Saúde havia realizado 808 atendimentos individuais, 53 visitas domiciliares e também 450 atendimentos via telefone (Boletim SMS, 2013).

Segundo Krum e Mafacioli (2016), na fase de assistência imediata à população, o Acolhe Saúde auxiliou de forma ativa nos atendimentos dos profissionais da saúde como forma de enfrentamento dos impactos físicos e do sofrimento psíquico. Os autores ressaltam que a assistência psicossocial, até final de março de 2013, foi prestada por muitos profissionais voluntários e, depois deste período, ocorreu uma seleção pública para contratação imediata de profissionais da saúde (psicólogos, psiquiatras, enfermeiros, técnicos de enfermagem, assistentes sociais e médico clínico geral). 
O apoio psicossocial no Acolhe Saúde foi realizado com intervenções conduzidas por uma equipe interdisciplinar. O primeiro acolhimento (primeira escuta, um trabalho de "portas abertas", sem necessidade de agendamento e encaminhamento) era desenvolvido por dois profissionais de núcleos técnicos diferentes e visava avaliar a integralidade do sujeito e sua demanda para construir a articulação do cuidado.

Para os psicólogos de orientação psicanalítica que participaram do atendimento, tornou-se necessário criar condições de enunciação para o que afetava os sujeitos. Elementos do traumático tomaram a cena dos relatos de inúmeros sobreviventes que procuraram o serviço. Um dado que surgiu nos atendimentos dos jovens era a preocupação em estabelecer uma borda entre suas vidas e o desastre, pois não queriam ser identificados como "sobreviventes da Kiss", e buscavam singularizar suas vivências nos seus atendimentos. Em seus discursos, eram frequentes os relatos de medo do escuro de permanecerem sozinhos, e dificuldade em permanecerem em locais fechados, como boates e similares. Muitos mencionaram hipervigilância, descrita como um permanente estado de alerta, verificando a presença ou ausência de extintores de incêndio e também certificando-se imaginariamente da possibilidade ou da criação de rotas de fuga. Vários sujeitos relataram que se sentiam seguros somente se permanecessem próximos de portas de saída.

Outros sintomas presentes nas suas falas foram: medo de novas perdas, quadros depressivos, reações fóbicas, reminiscências da vivência, sonhos traumáticos intrusivos e flashbacks de imagens súbitas, representativas do que vivenciaram. Alguns afirmaram que não serão mais os mesmos, que a vida mudou de sentido. Outros mencionaram uma percepção ligada à busca pela sobrevivência como um instrumento potente para ajudá-los a elaborar os fatos, mas sempre com a sensação de que o evento aconteceu ontem (Oliveira \& Dassoler, 2014).

Nos atendimentos, relatos com conteúdo mortífero se repetiam substancialmente, como sonhos com cenas de morte, de pessoas conhecidas ou deles próprios. Grande parte dos acolhidos apresentou alterações no sono, como insônia e dificuldade em administrar a escuridão em seu próprio quarto. Em inúmeros momentos, precisaram da companhia de outras pessoas para dormir, pois não se sentiam seguros. Outros relataram o aumento do uso de álcool ou outras drogas. Relatos de ideação suicida também se fizeram presentes nos discursos dos sujeitos.

Da Rosa (2014) formulou algumas hipóteses teóricas relativas ao impacto do trauma em pessoas envolvidas em situações de desastre, tal como o ocorrido na boate Kiss ou em acontecimentos similares, como o incêndio na boate Cromañón ${ }^{1}$, em Buenos Aires, em 2004. As situações de desastre despertam interesse no modo de organização do funcionamento psíquico dos pacientes/sobreviventes que vivenciaram uma situação traumática e mostram em seus discursos os fenômenos ligados à compulsão.

Os jovens falam como se o acontecimento tivesse uma temporalidade própria, em que é sempre presente. As lembranças remetem à busca pela sobrevivência e se reatualizam em outras situações. O gatilho da lembrança é acionado de modo diverso e imprevisível, porém articulado à história singular de cada um. Muitos desses jovens apresentaram uma fala similar à medida que relembraram a luta pela sobrevivência naquela situação de total desamparo, no desespero para sair daquele lugar e se livrar do sono causado pela fumaça tóxica que tomava conta do ambiente. As lembranças do momento do incêndio são fragmentadas: gritos, barulhos característicos do acionamento das ambulâncias e dos carros de bombeiros, lugares escuros e fechados, como um cinema, e a visualização de vultos. Esses elementos são consistentes com a fixação da vivência traumática e com a repetição constante do episódio doloroso sob a forma de sonhos ou de flashbacks (Freud, 1920/2010; Giacoia, 2008; Gondar, 2013; Lejarraga, 1996; Rodrigues \& Martinez, 2014; Uchitel, 2001).

Conforme Da Rosa (2014), o evento ocorrido é da ordem do traumático, pois uma situação de desastre como essa pode ter um impacto disruptivo na vida de inúmeras pessoas, que terão dificuldade para enfrentar uma realidade que provoca mal-estar e sofrimento. É um evento impossível de ser evitado ou antecipado, portanto o sujeito vive de modo passivo a sua intensidade, sem conseguir criar estratégias psíquicas que favoreçam o acionamento de um campo representativo devido à invasão súbita de elementos provocados pelo choque da realidade do desastre. Frente a isso, o aparelho psíquico apresenta dificuldade para processar e assimilar tal situação.

$\mathrm{Na}$ vivência traumática, o sujeito sente sua vida ameaçada. A sobrevivência física e psíquica fica fragilizada devido ao impacto da sobrecarga. A necessidade do organismo manter um equilíbrio entre o interior e o exterior invasivo aciona uma resposta defensiva imediata. No entanto, quando o aumento de excitação não consegue ser contido e ultrapassa a barreira de proteção, produzem-se as experiências traumáticas. Mediante a intensidade de energia desligada, o princípio do prazer

\footnotetext{
1194 pessoas morreram asfixiadas, em sua maioria jovens, em uma boate na República de Cromañón, em Buenos Aires, no dia 30 de dezembro de 2004, durante um show de rock. Segundo Carmo (2014), esse incêndio ocasionou mudanças tanto sociais como políticas no país. A legislatura argentina aprovou o impeachment do chefe de governo, pois este foi considerado responsável político pelo desastre. Outra mudança que ocorreu, segundo o jornal, é que houve uma conscientização e uma fiscalização maior nas normas de segurança nas boates daquele país. O incêndio que ocasionou a morte desses jovens ocorreu em decorrência de um show pirotécnico, cuja faíscas entraram em contato com a decoração do teto, constituída de tela de plástico inflamável de poliuretano. A combustão contaminou o ar com gases tóxicos e as pessoas ficaram intoxicadas, da mesma forma que aconteceu na Boate Kiss.
} 
fracassa e outros mecanismos são acionados para dominar o excesso, como a repetição (Lejarraga, 1996; Rudge, 2009; Uchitel, 2001).

Os sintomas repetitivos são produzidos como uma tentativa de domínio e representação do excesso, visando inverter a posição do sujeito de passivo para ativo na tentativa de exercer um controle da situação. Percebemos que a tendência de repetir o trauma, de certa forma, estaria relacionada ao princípio do prazer, pois sua função consistiria em reproduzir condições para uma descarga de energia acumulada, em uma tentativa de buscar o controle e de restaurar vias adequadas de escoamento, perturbadas pelo inesperado transbordamento de afluxo de energia (Giacoia, 2008).

Primo Levi, ao narrar sua vivência como prisioneiro de um campo de concentração nazista, afirmou que o tempo vivido no lager $^{2}$ movia-se como se a história tivesse parado (Levi, 1988). Gondar (2013) observa que a sensação de paralisação é frequente nas pessoas que vivenciaram situações traumáticas devido à ausência de domínio da energia pulsional, pois a vivência, não sendo representada psiquicamente, aparece para o sujeito como sempre atual e, por isso, apassiva o sujeito.

Como observamos nos relatos dos sobreviventes da boate, a expectativa da repetição, marcada por elementos como traçar rotas de fuga imaginárias e atenção ao extintores de incêndio, buscam reverter a posição passiva, transformando-a em uma postura de expectativa, visando despotencializar o fator surpresa e constituindo-se uma estratégia de defesa mais eficaz. No caso da vivência traumática, o trabalho da repetição busca, pelo desenvolvimento retroativo da angústia, realizar um movimento preparatório para o processo de ligação e de domínio das excitações decorrentes do evento traumático. Todavia, o resultado dessa busca pela liberação da energia desligada retrata a falha na ação da defesa e da angústia-sinal que deixou o campo livre para o impacto desorganizativo do fator surpresa/susto, produzindo uma sensação de perigo de morte (Giacoia, 2008; Uchitel, 2001).

Da Rosa (2014) ressalta, ao fazer um comparativo entre o incêndio na boate na Argentina (Cromañon) e o incêndio em Santa Maria, que uma das estratégias perceptíveis para suportar a experiência da vivência do desastre está ligada à posição subjetiva de cada vínculo e dos elementos reais, imaginários e simbólicos implicados na batalha pulsional entre a pulsão de vida e a pulsão de morte. A escuta psicanalítica foi destacada pela autora como uma possibilidade de transpor a sensação de vazio, de desamparo, possibilitando criar um caminho representacional para o trauma, reconstruir ativamente uma história para o sofrimento e o laço social abalado.

\section{O Enfrentamento do Traumático: A Construção de Narrativas}

O incêndio ocorrido na boate Kiss exigiu dos profissionais da psicologia ações de enfrentamento da situação de urgência subjetiva das pessoas atingidas em uma cidade enlutada. Como já foi descrito, os sintomas apresentados pelos sobreviventes provocaram dispêndio e sofrimento mental, ocupando permanentemente os sujeitos de tal modo que dificilmente conseguiriam reconstruir e reintegrar no discurso a experiência traumática do desastre sem a escuta psicanalítica. A angústia e a dificuldade em nomear o sofrimento também eram evidentes. A primeira escuta, de caráter de urgência, ofereceu um sentido precoce para a representação emocional da desorganização vivenciada pelos afetados, e gerou alívio para uma angústia devastadora e inominável na medida em que a percepção de um significado facilitou a reintegração psíquica (Benyakar, 2002; Thomé, 2012).

É preciso analisar a natureza contingente e única de cada situação traumática e também o efeito que suas irrupções incidem na vida do sujeito. $\mathrm{O}$ encontro com o real pode favorecer a exclusão do sujeito, bem como a não ligação com o seu desejo. O embate com o real é algo que não tem correspondência absoluta com o simbólico, pois são fatos que se apresentam sem qualquer antecipação, não se submetem a qualquer lei e rompem com a homeostase significante, ou seja, causam uma fratura no tipo de organização em que o eu se reconhecia. A relação transferencial dos afetados pelo desastre, construída com o psicanalista, mostrou-se um campo fértil de reconstrução e investimento das fantasias, assim como a possibilidade de uma organização psíquica por meio de uma narrativa (Rudge, 2009).

O testemunho é possível no encontro entre psicanalista e sujeito em sofrimento psíquico, através do qual há a oferta de uma escuta para que a fala ocorra. Nesse processo terapêutico, ambos os envolvidos são afetados. Se há uma escuta que viabilize a tradução para o horror do medo da morte, para a luta pela sobrevivência em um desastre, para cenas e imagens do desespero humano, é possível criar formas de ressignificar a experiência e reinventar outros sentidos para ela. Isso possibilitou a quebra do silenciamento que aprisiona o sujeito nas tramas da repetição, abriu caminhos para a recuperação da narrativa e reparação da memória, que oscila entre esquecer e não esquecer, e abriu também, ainda que minimamente, a possibilidade de um saber que torne vivível a cena traumática no psiquismo. Desta forma, o testemunho é a possibilidade de fazer história em atos criativos de vida (Conte, 2014; Perrone \& Moraes, 2014; Selligman-Silva, 2000).

2 Lager é o termo alemão referente ao campo de concentração nazista. 
O sofrimento traumático pode dificultar o processo de comunicação da experiência, pois há uma impossibilidade em simbolizar a vivência. O testemunho pode ser uma construção de memórias de múltiplas vozes, mas também pode ficar enclausurado no silêncio, o que ocorre quando pessoas traumatizadas não desejam se expor por não conseguirem traduzir em palavras o seu sofrimento. Diante disso, quem escuta deve considerar a importância da narrativa, pois, pelo diálogo construído através da alteridade, é possível a superação do trauma (Farias, 2012). Ao apropriar-se do testemunho, o sujeito, antes emudecido, passa a reconstruir sua experiência e a conectar a memória, o afeto e a representação em novos arranjos. Dessa forma, restitui suas capacidades de se pensar e se recompor (Perrone \& Moraes, 2014).

Alguns sobreviventes apresentavam discursos falhos, anestesiados para lembrar o que viveram no dia do incêndio. Mencionavam que não se lembravam como tinham saído do interior da boate, como receberam os primeiros socorros e o reencontro com seus familiares. Eles sentiam angústia significativa com essa espécie de rendição diante da força esmagadora do desastre, o encontro com a violência e a morte. A busca por essas lembranças foi possível no momento da oferta da escuta, ou seja, as cenas iam sendo reconstruídas à medida que o processo analítico ia avançando.

Nesses momentos iniciais pós-desastre, o olhar do psicanalista garantiu uma barreira contra a vitimização dos sujeitos, uma tendência natural e inconsciente da sociedade, com o intuito de preservar a memória histórica do desastre. A identificação como vítima paralisa o importante tensionamento entre esquecer e lembrar, que termina por operar uma narrativa do traumático, por isso entendemos as pessoas que sofreram impacto do traumático como afetadas e não como vítimas do desastre. As prioridades a serem acolhidas concernem às manifestações de cada indivíduo para que, no decorrer do processo terapêutico, o sujeito consiga enfrentar o evento e suas consequências singulares (Benyakar, 2002; Puel, 2012).

Nesse contexto, foi necessária uma postura mais ativa do psicanalista para auxiliar o paciente a nomear o acontecimento traumático, e para que os afetados pudessem começar a entender e traduzir os sentimentos confusos e assustadores, como o medo da morte, o medo de sequelas e a culpa pela perda de pessoas próximas. As funções psíquicas, como a capacidade de julgar, discriminar, sofrem uma desorganização que tem repercussões na memória e no saber. O trabalho do psicanalista junto aos afetados auxiliou-os a comunicar sua dor, importante para evitar que situações de sofrimento psíquico pós-desastre se cronifiquem (Benyakar, 2002; Thomé, 2012). Percebemos que o acompanhamento psicanalítico possibilitou aos afetados recriarem a vida cotidiana, com o objetivo de reconstruir minimamente as funções psíquicas, com consequente resgate das atividades diárias, reparando os vazios provocados pela experiência traumática do desastre.

Colocar os sujeitos diante da escuta clínica dos eventos traumáticos também foi de extrema importância pelo fato das imagens intrusivas, associadas aos eventos dessa natureza, serem consideradas as primeiras formas de ligação, prontas para receber investimentos e atingir a qualidade de representação. À medida que são investidas pelo desejo, as imagens fazem o processo primário funcionar, possibilitando a emergência do sentido, ainda que anteriores ao processo verbal. O sentido do traumático está intimamente relacionado à elaboração do trauma no momento em que as impressões traumáticas adquirem uma forma e, desse modo, podem ser elaboradas e traduzidas em palavras (Lejarraga, 1996).

\section{Considerações Finais}

A partir do relato da vivência dos profissionais que escutaram as pessoas afetadas direta e indiretamente pelo incêndio na boate Kiss, pudemos observar contornos do traumático como pontos significativos nos discursos. A escuta foi instrumento potente no sentido de ressignificar a vivência traumática, dando um suporte para enfrentar a dor, em função da perda de entes queridos ou da reorganização da vida, e a restauração do laço social, cujos parâmetros ficaram abalados.

Os sintomas da ordem do traumático são diversos, podem aparecer pelos sonhos, pelas fobias, pelos sintomas de repetição, pela presença constante do acontecido, o que gera angústia e sofrimento psíquico. Os pacientes atendidos precisavam criar um destino para a narrativa traumática por meio da criação de um espaço potencial que pudesse acolher esse tipo de demanda. A função terapêutica do psicanalista foi a de acolher a experiência traumática e auxiliar na produção de sentido. O testemunho da experiência singular de sujeitos afetados emocionalmente pelo desastre foi determinante para a apreensão da vivência traumática pelo psiquismo.

Pudemos perceber a estabilização dos sintomas apresentados pelos sujeitos atendidos pelos psicólogos de orientação psicanalítica. Os relatos iam se modificando no espaço de escuta, e a apreensão da vivência traumática pelo psiquismo foi possibilitando a retomada das atividades da vida diária, como frequentar a faculdade e ir a eventos sociais. Como resultado, houve a diminuição ou eliminação do medo do escuro e dos sintomas psicóticos, melhorando a qualidade do sono, resgatando os vínculos pessoais, assim como o desejo de investir em novos projetos de vida.

Frente ao horror da vivência ligada ao incêndio, o trabalho da psicanálise buscou marcar elementos simbólicos no discurso, mesmo que tais vivências tivessem poucos elementos de ligação e representação. A capacidade de narrar evidenciou o potencial humano de transmissão e significação de uma experiência. A narrativa acionou processos de simbolização e de 
organização da subjetividade frente a uma experiência de impacto desestruturante.

Sabemos que nem todas as pessoas que passaram por uma situação dessa ordem precisarão de escuta especializada, mas pudemos perceber que houve uma desorganização psíquica intensa e um número significativo de pessoas emocionalmente afetadas pelo ocorrido, e que, precisamente no hiato do traumático entre a percepção e a representação, a psicanálise teve uma função de estabelecer o percurso entre as rasuras, a suspensão, a ruína, até a linguagem que radicaliza o enfrentamento do impossível traumático.

\section{Referências}

Benyakar, M. (2002). Salud mental y desastres. Nuevos desafios: Revista Neurolpgía, Neurocirurgía y Psiquiatría, 351, 3-25.

Boletim Secretaria Municipal de Saúde de Santa Maria. (2013). Material impresso e dados do Acolhe Saúde. Santa Maria: Estado do Rio Grande do Sul.

Carmo, M. (2014). Dez anos depois, argentina realiza o sonho do filho morto em incêndio de boate. Recuperado de: http:// www.bbc.com/portuguese/noticias/2014/11/141125_mae_cromanon_mc

Cartilha para Intervenção em Catástrofe. (2009). Projeto: Psiquiatria para uma vida melhor. Florianópolis: Associação Brasileira de Psiquiatria, Governo do Estado de Santa Catarina.

Conte, B. S. (2014). Descomemoração dos 50 anos do Golpe. Diaphora, Revista da Sociedade de Psicologia do Rio Grande do Sul, 14(2),36-40.

Da Rosa, L. W. (2014). Familia y catástrofe: el incendio de la discoteca Kiss. Desvalimento Psicosocial, 1(1).

Dassoler, V. A., Mafacioli, G., Pacheco, M. L. L., Bueno, P., Sanfelice, M. M \& Fighera, C. (Orgs.). (2016). Acolhe saúde. A integração do cuidado diante do incêndio na boate Kiss: testemunhos e reflexões (pp. 133-144). Curitiba: CRV.

Dunker, C. (2006). A função terapêutica do real: trauma ato e fantasia. Pulsional, Revista de Psicanálise, 186,15-24.

Farias, F. (2012). Uma articulação entre o conceito de trauma e o de memória social: a elaboração da experiência traumática. Psicanálise \& Barroco em revista, 10(2),18-41.

Favero, A. B. (2009). A noção de trauma em psicanálise. Psicologia Clínica, 21(2), 485-490. https://doi.org/10.1590/S0103$\underline{56652009000200017}$

Freire, M. C. B. (2006). O som do silêncio isolamento e sociabilidade no trabalho de luto. Natal: Editora Universidade Federal do Rio Grande do Norte, 11(4), 38-64.

Freud, S. (1920/2010). Além do princípio do prazer. In S. Freud, Obras completas, História de uma neurose infantil, O homem dos lobos, Além do Princípio do prazer e outros textos (pp. 161-239). São Paulo: Companhia das Letras.

Fuks, M. P. (2010). Trauma e dessubjetivação. Trabalho apresentado no evento Herança e transmissão: trauma e narrativas nos espelhos da cultura. São Paulo: Departamento de Psicanálise do Instituto Sedes Sapientiae.

Giacoia, O. J. (2008). Além do princípio do prazer: um dualismo incontrolável. Rio de Janeiro: Civilização Brasileira.

Gondar, A. (2013). A escrita do traumático. Estudos da linguagem, 11(1),165-185.

Krum, A., \& Mafacioli, G. (2016). A organização do caos: a atenção psicossocial no Centro Desportivo Municipal (CDM). In G. Mafacioli, M. Lüdtke, M. L. L. Pacheco, M. M. Sanfelice, \& V. A. Dassoler (Orgs.), A integração do cuidado diante do incêndio na boate Kiss: testemunhos e reflexões (pp. 35-52). Curitiba: CRV. 
Laplanche, P. (2001). Vocabulário de psicanálise. São Paulo: Martins Fontes.

Lei no 12.608, de 10 de abril de 2012. Brasília: Diário Oficial da União. Acesso em: 9 jun. 2015. Disponível em: http://www. planalto.gov.br/ccivil_03/_Ato2011-2014/2012/Lei/L12608.htm

Lejarraga, A. L. (1996). O trauma e seus destinos. Rio de Janeiro: Revinter.

Levi, P. (1988). É isto um homem. Rio de Janeiro: Rocco.

Manual da Defesa Civil. (2012). Capacitação básica em defesa civil. Florianópolis: Universidade Federal de Santa Catarina. Acesso em: 2 jun. 2015. Disponível em: http://www.defesacivil.mg.gov.br/conteudo/arquivos/manuais/Livro_Defesa_ Civil_Completo.pdf.

Oliveira, S. B. C., \& Dassoler, V. A. (2014). Tempo, silêncio e esquecimento: o que ficou da experiência dos jovens de Santa Maria? Desidades, 4(2), 30-36.

Perrone, C. M., \& Moraes, E. G. (2014). Trauma e testemunho: caminho possível de subjetivação. In Sigmund Freud Associação Psicanalítica. Clínica do testemunho: reparação psíquica e construção de memória (pp. 31-48). Porto Alegre: Criação Humana.

Puel, E. (2012). Desastre natural e saúde mental: o Vale do Itajaí. In E. Puel, J. T. Thomé, \& Z. Feuzer (Orgs.), Depois das chuvas... o olhar de cuidado sobre o Vale do Itajaí: coletânea de artigos sobre vivências de profissionais que atuaram no trabalho de reconstrução/Santa Catarina (pp. 27-55). Florianópolis: Gerência da Coordenação da Atenção Básica.

Rodriguez, G. M., \& Martinez, V. V. (2014). A narrativa testemunhal e o endereçamento do traumático no psiquismo. Revista Latinoamericana de Psicopatologia Fundamental, 17(4), 858-871.https://doi.org/10.1590/1415-4714.2014v17n4p858.4

Rudge, A. M. (2009). Trauma. Rio de Janeiro: Jorge Zahar.

Selligman-Silva, M. A. (2000). História como trauma. In A. Nestrovski, \& M. Selligmann-Silva (Orgs.), Catástrofe e representação (pp.73-98). São Paulo: Escuta.

Thomé, J. T. (2012). Programa de Intervenção Emergencial e Suporte à População Atingida pela Catástrofe de Santa Catarina/2008. In E. Puel, J. T. Thomé, \& Z. Feuzer (Orgs.), Depois das chuvas... o olhar de cuidado sobre o Vale do Itajai: coletânea de artigos sobre vivências de profissionais que atuaram no trabalho de reconstrução/Santa Catarina (pp.17-25). Florianópolis: Gerência da Coordenação da Atenção Básica.

Uchitel, M. (2001). Neurose traumática. São Paulo: Casa do Psicólogo. 


\section{Endereço para correspondência}

\section{Alice Moreira da Costa}

End.: Rua Tuiuti 792/201, Bloco 5, Centro. Santa Maria/RS.

E-mail: alicemoreiradacosta@gmail.com

Maria Luiza Leal Pacheco

End.: Francisco Mariano da Rocha, 33/403, Centro. Santa Maria/RS.

E-mail: malulpacheco@bol.com.br

Cláudia Maria Perrone

End.: Avenida Roraima, 1000, Departamento de Psicologia, Bloco B, Sala 1304.

E-mail: cmperrone@ig.com.br 